\title{
DEMOCRATIZAÇÃO DO ACESSO E DA PERMANÊNCIA NO ENSINO SUPERIOR: AÇÕES E EXPERIÊNCIAS NA UNIVERSIDADE FEDERAL DO RIO GRANDE DO NORTE.
}

\author{
E.M.B.Pereira $^{1}$; D.S.Tinôco ${ }^{1 *}$ e J.M.L.Alloufa ${ }^{1^{*}}$ \\ 1 Universidade Federal do Rio Grande do Norte, 59078-900, Natal-RN, Brasil. \\ *ericmatheus.bispo@hotmail.com
}

\section{RESUMO}

Democratizar o ensino superior é ampliar o acesso à educação à todos os membros da sociedade, especialmente àqueles dela excluídos. Este artigo tem como objetivo compreender as ações inovadoras adotadas na Universidade Federal do Rio Grande do Norte (UFRN), no apoio à democratização do acesso e da permanência de estudantes socialmente carentes, destacando as principais características do Programa Complementar de Estudos do Ensino Médio (PROCEEM) e as configurações de alguns auxílios estudantis disponibilizados aos discentes da Universidade. Trata-se de uma pesquisa qualitativa, exploratória, bibliográfica, documental e de campo, cujos dados foram obtidos em
\end{abstract}

documentos oficiais, além de entrevistas semiestruturadas com coordenadores das ações de apoio aos estudantes e com alguns beneficiários. Os resultados evidenciam que o PROCEEM auxilia no aumento das oportunidades de acesso e consequentemente nas possibilidades de aprovação dos estudantes de escolas públicas, capacitando-os gratuitamente na matriz curricular do ENEM. Em relação às ações de apoio à permanência do estudante socialmente carente, além de reduzir os índices de evasão estudantil, proporcionam apoio financeiro para a manutenção do aluno e previne situações que possam reduzir seu bom desempenho acadêmico.

PALAVRAS-CHAVE: democratização, ensino superior, UFRN.

\section{DEMOCRATIZATION OF ACCESS AND STAY IN COLLEGE EDUCATION: ACTIONS AND EXPERIENCES AT FEDERAL UNIVERSITY OF RIO GRAND EDO NORTE.}

\section{ABSTRACT}

Democratizing college education means amplifying access to education to all society members especially for those who were left aside of it. This article aims to understand groundbreaking actions adopted by Universidade Federal do Rio Grande do Norte (UFRN), supporting the democratization in the insertion and permanence of socially disadvantaged students describing the main characteristics of the Programa Complementar de Estudos do Ensino Médio (PROCEEM) and the configurations of some assistance available to students of UFRN. This article regards a qualitative, explorative, bibliographic, documented and field survey whose data
\end{abstract}

have been obtained in affidavits documents and semi structured interviews with project coordinators and some beneficiaries of those policies. The results show that the PROCEEM helps increasing the access opportunities and thus the possibilities of approval of students from public schools, giving them free access to knowledge required for ENEM. In relation to these supporting actions to the permanence of socially disadvantaged students besides reducing the rates of student's evasion, they bring financial support for the maintenance of the students and they prevent situations that may reduce their academic development in college.

KEYWORDS: democratization, college education, UFRN. 


\section{INTRODUÇÃO}

No cenário internacional, como entidade promotora da paz, da segurança e do desenvolvimento social dos países, a Organização das Nações Unidas para a Educação, Ciência e Cultura define a educação superior como um bem público, sendo uma importante ferramenta na redução da disparidade que separa os países em desenvolvimento dos desenvolvidos, sem a qual não é possível formar cidadãos críticos (UNESCO, 2009).

No Brasil, as configurações do ensino superior, bem como o desenvolvimento de políticas públicas educacionais, possuem como uma das bases de sustentação a Constituição Federal de 1988, que em seu artigo 205 estabelece que a educação é um direito de todos e dever do Estado e da família e objetiva o desenvolvimento do indivíduo, seu preparo para o exercício da cidadania e sua qualificação para o trabalho. (BRASIL, 1988).

Segundo dados do Censo da Educação Superior (INEP, 2012) existem cerca de sete milhões de estudantes matriculados nessa modalidade de ensino no Brasil, dos quais aproximadamente cinco milhões estão vinculados a instituições de ensino privadas e dois milhões a instituições públicas. Nessa conjuntura, Santos (1996) destaca que as universidades públicas vêm sendo frequentadas predominantemente por alunos provenientes das classes sociais mais elevadas, com maior poder aquisitivo e consequentemente maiores condições de arcar com um ensino médio preparatório e de qualidade para os processos seletivos.

Em 2001, surge o Plano Nacional de Educação 2001-2010, tendo sua versão atualizada no Projeto de Lei do PNE de 15 de dezembro de 2010. O documento apresenta dez diretrizes e vinte metas, seguidas de estratégias específicas de concretização. Dentre elas, estão as relacionadas à ampliação das oportunidades de acesso ao nível superior, tendo como principais estratégias o aumento do número de estudantes egressos da escola pública e a ampliação da participação proporcional de grupos historicamente desfavorecidos, inclusive mediante a adoção de políticas afirmativas. (BRASIL, 2011).

O Plano, unido às recentes ações afirmativas adotadas pelo Governo, retoma o conceito de democratização. Ristoff e Sevegnani (2006) definem que a democratização dar-se-á com a formulação de políticas que visem tornar o ensino, em especial o superior, acessível a todas as classes, sem distinções econômicas, sociais e raciais. Complementando, tem-se que o conceito não engloba somente questões de acesso, como também a garantia de que esses estudantes terão condições de se manter no ambiente acadêmico. (TEIXEIRA, et al 2012).

Historicamente, constata-se no Brasil a existência de elevados índices de desigualdade social, que em um mundo globalizado e interligado se refletem não só na perspectiva econômica, como também na educacional. (HERMIDA, 2006). Nesse aspecto, nota-se que o cenário da educação superior brasileira configura-se ao longo dos anos como um ambiente seletivo e - por muitas vezes - elitista. Taborda et al (2006) justificam que o sistema é seletivo, pois se baseia na meritocracia, inferindo-se que os candidatos possuem iguais condições de oportunidades, diferenciando-se a partir do mérito individual. Em um país em que a renda de $10 \%$ da população mais rica representa 30 vezes a renda média de $40 \%$ da população mais pobre, cogitam-se outras interpretações à proposição. (QUEIROZ, 2007).

Diante do compromisso social da Universidade, que segundo Wanderley (2005) é o de, dentre outros, colaborar para a transformação da sociedade, responder aos interesses universais e atender aos setores carentes, surge no Brasil as ações de democratização do ensino superior. Tais ações ganham relevância nos anos 1990, diante das significativas alterações do setor, destacando-se 
as mudanças na estrutura acadêmica, nos processos de avaliação, nas diretrizes curriculares e na ampliação da oferta de vagas. (CATANI e OLIVEIRA, 2002).

Democratizar o ensino superior é, portanto, ampliar o acesso à educação a todos os membros da sociedade - independente da classe social, cor ou raça - processo que deve ocorrer concomitantemente à criação de estratégias que garantam condições dos alunos manterem seus estudos, sem haver perda de qualidade educacional (ZANDONÁ, 2005). Nesse aspecto, as ações de democratização trazem em seu escopo o desafio de ser uma nova resposta, socialmente aceita e conhecida, capaz de gerar mudança de paradigmas.

Nesse sentido, é importante ressaltar as ações afirmativas, que são associadas, na maioria das vezes, à reserva de vagas para negros em Instituições de Ensino. Porém, como política pública, sua aplicação também se estende a outros grupos sociais. Gomes e Martins (2004); Peixoto (2004) as definem como um conjunto de políticas públicas de caráter compulsório ou facultativo, desenvolvidas sob a ótica da discriminação racial, social e de gênero, para atenuar os efeitos da discriminação praticada no passado, objetivando concretizar os ideais de igualdade de acesso à educação e formação profissional.

No campo internacional, o país que primeiro as adotou foram os Estados Unidos, que pretendiam criar programas que apresentassem objetivos e procedimentos que traduzissem um esforço na equalização da oferta de empregos a grupos historicamente excluídos. (WASHINGTON; HARVEY, 1999).

Entre as ações de democratização adotadas pelo Governo brasileiro e amplamente discutidas no ambiente político e social do país está a Lei de Cotas, que estabeleceu que por dez anos a partir de agosto de 2012, é garantido no ensino brasileiro 50\% das vagas das Universidades Federais e dos Institutos Federais de Educação, Ciência e Tecnologia aos alunos que estudaram durante todo o ensino médio em escola pública, sendo subdivididas em cotas sociais e cotas raciais (BRASIL, 2012). A Lei número 12.711/2012 de 30 de agosto de 2012 estabelece os critérios que definem a política, tendo em síntese os seguintes itens reguladores:

Cotas sociais: do total de vagas designadas aos alunos egressos de escolas públicas, metade é destinada a estudantes com renda familiar bruta igual ou inferior a 1,5 salários mínimos per capita e metade para aqueles com renda familiar superior a 1,5 salários mínimos.

Cotas raciais: para cada uma dessas condições de renda, um percentual das vagas é destinado a quem se autodeclarar preto, pardo ou indígena na mesma proporção em que esses segmentos são encontrados no estado onde está instalada a instituição de ensino, de acordo com o mais recente censo do IBGE.

$\mathrm{Na}$ outra vertente, Mello, Silva e Moura (2006) citam que as políticas de cotas não exercem o efeito desejado no combate à exclusão socioeducacional, em função de seu caráter político, sendo utilizadas para fins eleitorais. Corroborando, questiona-se que a adoção e aceitação dessa política legitimem uma ação paliativa para enfrentar as situações de desigualdades na sociedade brasileira, visto que a origem do problema (falta de investimento nos níveis de ensino iniciais) continua persistindo. (LEITE, 2011).

Se a democratização do acesso implica na expansão da rede pública, ampliando a oportunidade de ingresso de alunos socialmente carentes, a democratização da permanência envolve a manutenção e expansão dos programas de assistência (FONAPRACE, 1993). Programas que surgiram das lutas históricas de dirigentes, docentes e discentes, em torno da assistência estudantil enquanto um direito social voltado para igualdade de oportunidades aos estudantes do ensino superior. Corroborando, Vasconcelos (2010) acrescenta que essas ações são também, parte importante no processo evolutivo e de formação. 
Com o aumento na oferta de vagas, as Instituições de Ensino Superior públicas passam a receber um contingente significativo de novos estudantes, muitos deles em condições socioeconômicas desfavoráveis. Como diz Costa (2009) a universidade é uma expressão da própria sociedade brasileira, e por isso abriga as contradições nela existentes.

Para minimizar essas contradições e as dificuldades dos estudantes socialmente carentes aprovados, foi regulamentado através do Decreto 7.234, de 19 de julho de 2010, o Programa Nacional de Assistência Estudantil (PNAES) executado no âmbito do Ministério da Educação, com a finalidade de ampliar as condições de permanência dos jovens na educação superior pública federal, no nível de graduação. (BRASIL, 2010). O Programa configura-se em quatro áreas estratégicas, sendo elas as de permanência; desempenho acadêmico; cultura; lazer e esporte; assuntos da juventude.

As linhas temáticas relacionadas às ações de permanência estão transcritas nos seguimentos de moradia, alimentação, saúde, transporte e creche. Na estratégia do desempenho acadêmico, destacam-se as bolsas, estágios remunerados, ensino de línguas, inclusão digital, fomento à participação político-pedagógico e acompanhamento psicopedagógico oferecidos pelas IES aos estudantes. Na cultura, lazer e esporte, têm-se como temas o acesso à informação e difusão das manifestações artísticas e culturais e o acesso a ações de educação esportiva, recreativa e de lazer. Por fim, nos assuntos da juventude, as linhas temáticas envolvidas são as de orientação profissional, sobre mercado de trabalho, prevenção a fatores de risco, meio ambiente, política, ética e cidadania, saúde, sexualidade e dependência química.

Finatti (2007) retrata que o PNAES surge em um cenário onde as dificuldades não se encontram somente no ingresso, mas também na permanência, visto que os alunos possuem gastos com transporte, alimentação, material didático, entre outros. Esses custos são as principais causas que aumentam os índices de evasão estudantil do estudante socialmente carente. (ANDIFES, 2011).

Diante do exposto, surge o seguinte problema de pesquisa: de que forma os programas de democratização do acesso e da permanência atuam como inovações no ensino superior brasileiro? Com isso, busca-se esclarecer as ações afirmativas e de assistência estudantil aplicadas na Universidade Federal do Rio Grande do Norte. Para tanto, tem-se os seguintes objetivos específicos: i) compreender o escopo do Programa Complementar de Estudos do Ensino Médio (PROCEEM), suas características e formas de atuação, ii) evidenciar como o Programa auxilia na democratização do acesso ao ensino superior de estudantes provenientes de escolas públicas; iii) identificar as principais ações de apoio à permanência dos alunos socialmente carentes aprovados na UFRN.

\section{MATERIAIS E MÉTODOS}

O presente artigo caracteriza-se como uma pesquisa qualitativa e quanto ao objetivo, como descritiva e exploratória (GIL, 1999). Buscou-se descrever como o cursinho da UFRN e as ações de assistência estudantil desenvolvidas na Universidade influenciam na democratização do acesso e da permanência dos estudantes socialmente carentes. É exploratória, na medida em que procurou conhecer com maior profundidade o tema, que além de bastante discutido no cenário nacional, ainda é pouco explorado na UFRN.

Quanto aos procedimentos, trata-se de uma pesquisa bibliográfica e documental, em que foram consultados materiais disponíveis e a legislação vigente que trata do PNAES - Programa Nacional de Assistência Estudantil e Lei de Cotas.

Identifica-se de que forma o Programa Complementar de Estudos do Ensino Médio (PROCEEM) auxilia na preparação dos candidatos socialmente carentes a prestar o Exame Nacional do Ensino Médio (ENEM), relatando-se os auxílios oferecidos pela Pró-reitoria de 
Assuntos Estudantis (PROAE) e suas contribuições na permanência dos alunos aprovados na instituição.

Propõem-se demonstrar experiências de aprofundamento em questões relevantes sobre o fenômeno pesquisado (democratização no ensino superior público), buscando enfatizar a multiplicidade de dimensões do problema. Para tanto, procurou elucidar os caminhos adotados pela UFRN no enfrentamento da questão, a partir da opinião dos principais gestores do programa estudado, bem como com alguns beneficiários.

$\mathrm{Na}$ coleta de dados, utilizou-se de entrevista semi-estruturada com beneficiários e coordenadores de projetos que tratam da temática da democratização do ensino, permitindo a captação imediata da informação desejada, auxiliando a percepção de características abrangentes e de importância para retratar o Programa em foco.

As entrevistas foram realizadas com o Pró-Reitor Adjunto de Assuntos Estudantis da UFRN; com um dos supervisores do Programa PROCEEM; duas alunas do Programa; uma beneficiária do auxílio atleta; um favorecido pela bolsa residência e um beneficiado pela bolsa alimentação, totalizando sete pessoas, conforme demonstrado no Quadro 2.

Quadro 1 - Relação dos Entrevistados e informações sobre as entrevistas.

\begin{tabular}{|c|c|c|c|}
\hline Local da entrevista & Nomeação & Função & Dia \\
\hline $\begin{array}{l}\text { Gabinete da Pró-Reitoria de Assuntos } \\
\text { Estudantis da UFRN }\end{array}$ & Entrevistado 1 & $\begin{array}{l}\text { Pró-Reitor Adjunto } \quad \mathrm{de} \\
\text { Assuntos Estudantis }\end{array}$ & 3 de julho de 2014 \\
\hline $\begin{array}{l}\text { Secretaria administrativa do Programa } \\
\text { PROCEEM }\end{array}$ & Entrevistado 2 & $\begin{array}{l}\text { Membro da coordenação do } \\
\text { PROCEEM }\end{array}$ & 7 de julho de 2014 \\
\hline Setor de aulas III - Bloco $\mathrm{G}$ - sala 3 & Entrevistado 3 & Aluna do PROCEEM & 4 de julho de 2014 \\
\hline Setor de aulas III - Bloco $\mathrm{G}-$ sala 4 & Entrevistado 4 & Aluna do PROCEEM & 4 de julho de 2014 \\
\hline Setor de aulas I - Bloco F - sala 2 & Entrevistado 5 & Beneficiária do auxílio atleta & 7 de julho de 2014 \\
\hline Setor de aulas $\mathrm{I}-\mathrm{Bloco} \mathrm{F}-$ sala 3 & Entrevistado 6 & $\begin{array}{l}\text { Beneficiária } \quad \text { da } \quad \text { bolsa } \\
\text { residência }\end{array}$ & 8 de julho de 2014 \\
\hline Restaurante Universitário. & Entrevistado 7 & $\begin{array}{lll}\begin{array}{l}\text { Beneficiária } \\
\text { alimentação }\end{array} & \text { da } & \text { bolsa } \\
\end{array}$ & 2 de julho de 2014 \\
\hline
\end{tabular}

Fonte: elaborado pelo autor

As perguntas foram formuladas com o objetivo de identificar, dentre outros, os seguintes aspectos: cenário em que começou a ser discutido a democratização do acesso e da permanência de alunos socialmente carentes na UFRN; delimitação e elaboração do orçamento destinado às ações; principais benefícios e críticas aos projetos; perfil e número dos beneficiários, e as influências das ações no cotidiano dos universitários.

\section{RESULTADOS E DISCUSSÃO}

\subsection{O Programa Complementar de Estudos do Ensino Médio (PROCEEM): histórico, características e formas de atuação.}

Os primeiros cursinhos, como também os mais numerosos, são organizações privadas que visam lucro, sempre tendo como público alvo a parte da população dotada de boa condição financeira. (MOEHLECKE, 2002). O Governo, dirigentes de Instituições de Ensino Superior e estudiosos das políticas educacionais notaram que a mudança desse cenário seria iniciada com a capacitação gratuita dos alunos do ensino médio de escolas públicas. No âmbito da UFRN, surge em 2007, como iniciativa da Pró Reitoria de Graduação (PROGRAD),o Programa Complementar 
de Estudos do Ensino Médio (PROCEEM), objetivando ampliar as expectativas e oportunidades de acesso à Universidade aos estudantes de famílias pobres.

Com turmas de em média cinquenta alunos, o "Cursinho da UFRN" destaca-se ao abrir processo seletivo duas vezes por ano a estudantes socialmente carentes de escolas públicas, para que os candidatos tenham aulas gratuitas de ciências biológicas, geografia, física, história, português, literatura, inglês, letras, espanhol, matemática, química, filosofia e sociologia.

Além de beneficiar os estudantes, o cursinho também possibilita que os discentes da UFRN consigam unir teoria à prática, uma vez que todas as aulas são ministradas por estudantes da universidade. Entrevistado 2.

Através de parceria firmada com a Secretaria de Educação do Rio Grande do Norte, no primeiro ano de funcionamento as aulas do cursinho eram oferecidas no campus da UFRN em Natal e mais algumas escolas pré-selecionadas em municípios do estado, especificamente nas cidades de Goianinha, Nova Cruz, Ceará-Mirim, Currais Novos, Caicó e João Câmara. Na época,o programa atendeu em média dezoito turmas com 50 alunos distribuídas em 15 escolas, atingindo um total de cerca 1.000 alunos atendidos.

Fica evidente o apoio dado pela Secretaria de Educação no início do projeto, através da parceria pudemos planejar turmas e horários que atendessem várias regiões do estado, relata o entrevistado 2.

A partir de 2008, o convênio com a Secretaria da Educação do RN foi suspenso e as aulas passaram a ser ministradas apenas nos campus na UFRN em Natal, Caicó, Currais Novos, Santa Cruz e em uma única escola estadual da capital. Segundo a coordenação do Programa, o término da parceria além de reduzir o número de turmas ofertadas no interior, centralizou as atividades nas regiões em que a universidade já possui campus instalado.

Nesse cenário, o REUNI - Programa de Apoio a Planos de Reestruturação e Expansão das Universidades Federais, torna-se ferramenta de apoio na expansão das atividades, pois além de garantir os recursos financeiros necessários para pagamento de bolsistas, respaldou o Programa.

Em 2014, o cursinho funciona com a estrutura explícita na Tabela 1, com oito turmas na UFRN (cinco no período da tarde e três à noite), funcionando nos setores de aula I e III e no Departamento de Enfermagem, ambas de segunda a sexta-feira. Além disso, há uma turma em escola estadual da zona norte da capital. No interior, há onze turmas formadas, sendo quatro na cidade de Caicó; três em Santa Cruz e quatro em Currais Novos.

Tabela 1 - Estrutura de funcionamento do Programa PROCEEM na UFRN em 2014.

\begin{tabular}{|c|c|c|c|c|}
\hline Polo & Local & $\begin{array}{l}\text { Quantidade de } \\
\text { turmas }\end{array}$ & Turno & Dias de realização \\
\hline UFRN - Natal & Setor de aulas I e III & 5 & Vespertino & Segunda a sexta \\
\hline UFRN - Natal & Dept. de Enfermagem & 3 & Noturno & Segunda a sexta \\
\hline $\begin{array}{l}\text { Zona Norte Natal - } \\
\text { bairro da Redinha }\end{array}$ & $\begin{array}{lr}\text { Escola } & \text { Estadual } \\
\text { professora } & \text { Dulce } \\
\text { Wanderley } & \\
\end{array}$ & 1 & Noturno & Segunda a sexta \\
\hline UFRN-Campus Caicó & Setor de aulas teóricas & 4 & Vespertino & Segunda a sexta \\
\hline $\begin{array}{l}\text { UFRN }- \text { Campus } \\
\text { Santa Cruz }\end{array}$ & Bloco "A" e bloco "B" & 3 & $\begin{array}{l}\text { Matutino/vespertino/n } \\
\text { oturno }\end{array}$ & $\begin{array}{l}\text { Quinta e sexta - noite / } \\
\text { sábado e domingo - manhã } \\
\text { e tarde. }\end{array}$ \\
\hline $\begin{array}{l}\text { UFRN }- \text { Campus } \\
\text { Currais Novos }\end{array}$ & Setor de aulas teóricas & 4 & Vespertino & Segunda a sexta \\
\hline
\end{tabular}

Fonte: elaborado pelo autor.

Segundo Adorno (2000), tão necessário quanto à expansão das vagas gratuitas em cursos preparatórios para alunos socialmente carentes, é a discussão sobre as formas de seleção dos 
candidatos. Questionada sobre o assunto, a coordenação do PROCEEM, informou que não há uniformização de procedimento de seleção, ou seja, ocorrem segundo contextos situacionais.

Na nossa primeira seleção de 2014 , dada a elevada quantidade de candidatos, utilizamos a meritocracia. Aqueles que tinham maior nota nas disciplinas de português e matemática enquanto cursam ou cursavam o ensino médio eram classificados. Entrevistado 2.

Ao longo do primeiro semestre, verificou-se que a taxa de evasão desses alunos chegou a cerca de $30 \%$, levando a coordenação a avaliar se realmente o método adotado tinha sido o mais eficiente. Para preencher as vagas remanescentes, foi realizado um novo processo seletivo em maio para início das aulas em julho. Neste, optaram por realizar a seleção baseado na ordem de chegada dos candidatos.

A mudança foi pensada a partir do pressuposto que os mais interessados seriam os que chegariam primeiro, em outras palavras, "para tentar facilitar a entrada de quem realmente quer fazer o curso", relata a coordenação do PROCEEM. Sobre a efetividade desse novo processo, infere-se que ainda não é possível medi-lo, dado o recente inicio do semestre letivo.

No tocante aos professores, todos são estudantes da UFRN, preferencialmente de licenciaturas e selecionados mediante condições estabelecidas em edital divulgado pela coordenação. O instrumento convocatório em 2014 foi o Edital 001/2014, que além de prevê a quantidade de vagas oferecidas, remuneração e regime de trabalho, estabelece as condições de seleção. As tabelas 2 e 3 sintetizam as principais informações do certame.

Tabela 2 - Descrição das vagas para professores do PROCEEM nas turmas de Natal.

\begin{tabular}{|c|c|c|c|c|c|}
\hline UNIDADES & $\begin{array}{l}\text { DISCIPLINA } \\
\text { AREA DE } \\
\text { CONHECIMENTO }\end{array}$ & VAGAS & $\begin{array}{l}\text { CADASTRO } \\
\text { RESERVA* }\end{array}$ & $\begin{array}{l}\text { REGIME DE TRABALHO } \\
\text { ( } 20 \text { horas semanais) }\end{array}$ & REMUNERAÇÄO \\
\hline \multirow{12}{*}{$\begin{array}{l}\text { SETOR I } \\
\text { DEP. de } \\
\text { ENFERMAGEM } \\
\text { REDINHA }\end{array}$} & L.PORTUGUESA & 02 & 04 & $\begin{array}{l}\text { 10 h semanais de docência } \\
+10 \mathrm{~h} \text { para planejamento }\end{array}$ & $\mathrm{R} \$ 550,00$ \\
\hline & MATEMÁTICA & 02 & 04 & $\begin{array}{l}10 \mathrm{~h} \text { semanais de docência } \\
+10 \mathrm{~h} \text { para planejamento }\end{array}$ & $\mathrm{R} \$ 550,00$ \\
\hline & HISTORIA & 02 & 04 & $\begin{array}{l}10 \mathrm{~h} \text { semanais de docência } \\
+10 \mathrm{~h} \text { para planejamento }\end{array}$ & $\mathrm{R} \$ 550,00$ \\
\hline & FÍSICA & 02 & 04 & $\begin{array}{l}10 \mathrm{~h} \text { semanais de docência } \\
+10 \mathrm{~h} \text { para planejamento }\end{array}$ & $\mathrm{R} \$ 550,00$ \\
\hline & BIOLOGIA & 02 & 04 & $\begin{array}{l}10 \mathrm{~h} \text { semanais de docência } \\
+10 \mathrm{~h} \text { para planejamento }\end{array}$ & $\mathrm{R} \$ 550,00$ \\
\hline & QUÍMICA & 02 & 04 & $\begin{array}{l}10 \mathrm{~h} \text { semanais de docência } \\
+10 \mathrm{~h} \text { para planejamento }\end{array}$ & $R \$ 550,00$ \\
\hline & SOCIOLOGIA & 02 & 04 & $\begin{array}{l}10 \mathrm{~h} \text { semanais de docência } \\
+10 \mathrm{~h} \text { para planejamento }\end{array}$ & $R \$ 550,00$ \\
\hline & GEOGRAFIA & 02 & 04 & $\begin{array}{l}10 \mathrm{~h} \text { semanais de docência } \\
+10 \mathrm{~h} \text { para planejamento }\end{array}$ & $\mathrm{R} \$ 550,00$ \\
\hline & FILOSOFIA & 02 & 04 & $\begin{array}{l}10 \mathrm{~h} \text { semanais de docência } \\
+10 \mathrm{~h} \text { para planejamento }\end{array}$ & $\mathrm{R} \$ 550,00$ \\
\hline & INGLES & 02 & 04 & $\begin{array}{l}10 \mathrm{~h} \text { semanais de docência } \\
+10 \mathrm{~h} \text { para planejamento }\end{array}$ & $\mathrm{R} \$ 550,00$ \\
\hline & ESPANHOL & 02 & 04 & $\begin{array}{l}10 \mathrm{~h} \text { semanais de docência } \\
+10 \mathrm{~h} \text { para planejamento }\end{array}$ & $\mathrm{R} \$ 550,00$ \\
\hline & TOTAL & 22 & 44 & & \\
\hline
\end{tabular}

Fonte: PROCEEM, 2014.

São oferecidas 66 vagas em Natal, sendo vinte e duas para inicio imediato e quarenta e quatro para formação de cadastro reserva. O regime de trabalho é 20 horas semanais, distribuídos de forma igualitária para a docência e planejamento de aulas. Nas cidades do interior, são oferecidas 45 vagas, vinte e sete para início imediato e dezoito de cadastro reserva, com as mesmas características das ofertadas na capital. A diferença é que não existem vagas em filosofia e sociologia, em virtude de não haver esses cursos nos campi da UFRN no interior.

A remuneração dos bolsistas é de $\mathrm{R} \$ 550,00$ reais, ao custo fixo mensal de $\mathrm{R} \$ 26.950,00$ (levando-se em consideração apenas as quarenta e nove vagas de inicio imediato). O pagamento é oriundo de recursos orçamentários da UFRN e configuram-se como a principal despesa do Programa. 
No ano em que houve parceria com o Governo do Estado, havia uma contrapartida financeira que auxiliava no pagamento dos bolsistas, mas agora que não existe o convênio, a UFRN arca com os custos, finaliza o Entrevistado 2.

Tabela 3 - Critérios de seleção para professores do PROCEEM - 2014.

\begin{tabular}{|l|l|c|c|}
\hline Itens & Critério & Nota & Atribuída \\
\hline 1 & $\begin{array}{l}\text { Ter experiência comprovada em projetos de cursinho atuando como } \\
\text { docente (01 ponto por ano letivo, máximo de 03 pontos). }\end{array}$ & $0-3$ & \\
\hline 2 & $\begin{array}{l}\text { Exercício de monitoria em nível superior, programas e/ou projetos de } \\
\text { ensino ou inovaçäo pedagógica (0,25 pontos por semestre, máximo de 01 } \\
\text { ponto). }\end{array}$ & $0-1$ & \\
\hline 3 & Ser aluno de Curso de licenciatura ou já licenciado. & 04 & \\
\hline 4 & $\begin{array}{l}\text { Estar registrado no CADASTRO ÚNICO do SIGAA e ser aluno } \\
\text { preferencial. }\end{array}$ & 02 & \\
\hline & \multicolumn{1}{|r|}{ Total } & 10,0 & \\
\hline
\end{tabular}

Fonte: PROCEEM, 2014.

O cadastro dos alunos interessados ocorreu de 13 a 18 de fevereiro de 2014, através de solicitação de inscrição preenchida enviada via e-mail com documentos comprobatórios anexados. A Tabela 3 evidencia os critérios de seleção para os professores, nos quais a Comissão de Seleção aplicou notas de 0 a 10 segundo os títulos solicitados. Aqueles que possuíam experiência em atividades que unam a tríade universitária (ensino-pesquisa-extensão) se diferenciavam na pontuação dos demais, principalmente aqueles que lecionavam em atividades de monitoria ou em outros cursinhos.

Essa definições evidenciam que o PROCEEM além de contribuir no acesso do estudante socialmente carente à UFRN, também apoia aquele que já é acadêmico nessa situação, uma vez que o Item 4 refere-se diretamente ao aspecto da democratização, dado que os alunos vinculados ao "Cadastro Único do SIGAA", são aqueles socialmente carentes, garantido a eles 2,0 pontos na classificação final. Os aprovados participam de uma oficina pedagógica obrigatória de uma semana antes de ministrar as aulas.

Questionaram-se também os pontos a melhorar na execução das atividades do Programa: de forma unânime, os entrevistados 2, 3 e 4 citaram que a própria atuação dos professores requer maior atenção, pois ainda não há ferramentas eficazes na medição do desempenho dos bolsistas.

\subsection{O PROCEEM como estratégia na democratização do acesso à Universidade Federal do Rio Grande do Norte.}

"Obviamente há muitos candidatos que fazem cursinho e não entram nas universidades públicas, mas são pouquíssimos os que entram sem cursinho” (HAMBURGUER, 1987, p. 13). Corroborando, Whitaker e Fiamengue (2001) citam que os concorridos processos seletivos, diante de suas exigências e critérios, culminam por auxiliar no distanciamento dos alunos socialmente carentes da Universidade. Não por falta de mérito dos mesmos, mas sim, porque são em sua maioria provenientes de escolas públicas com ensino defasado. No enfrentamento dessa questão, a UFRN executa desde o ano de 2007 o "Programa Complementar de Estudos para Estudantes do Ensino Médio (PROCEEM)", popularmente conhecido como "Cursinho da UFRN".

Baseado nessas informações verifica-se que a origem do Programa vincula-se ao compromisso institucional de democratizar o acesso de alunos socialmente carentes à universidade pública. (UFRN, 2010). Durante a entrevista, a coordenação afirma que o cursinho atua não só no aspecto político-pedagógico, como também no motivacional, pois dada o descompasso no ensino médio evidenciado em muitas escolas públicas, o aluno não consegue por si só, se ver no ambiente acadêmico. 
O PROCEEM, além de democratizar o acesso de estudantes socialmente carentes, torna-se ferramenta de motivação ao estudante da escola pública. Entrevistado 2.

Nessa vertente, perguntou-se aos discentes do cursinho se acham que teriam condições de serem aprovados no ENEM, caso não estivessem matriculados no PROCEEM. As respostas, conforme relatos abaixo evidenciam o descrédito do ensino médio na rede pública, o que segundo Araújo (2007) é causado não por um único fator, mas sim pela conjuntura histórica em que Governo, professores, diretores e alunos estão inseridos.

Não vejo meus professores incentivando os alunos a prestarem o ENEM. Os recém-chegados até falam da importância da prova, mas não o suficiente para estimular. Entrevistado 3.

Sei da realidade do ensino público, mas no meu caso foi diferente. Tive a oportunidade de cursar o $3^{\circ}$ ano em uma escola no interior e nela, havia preparação e incentivo aos alunos que queriam ingressar na universidade. Se fosse a antiga escola que estudei, a situação era totalmente o contrário. Entrevistado 4.

Para melhor detalhar o perfil dos alunos do PROCEEM que foram entrevistados, criou-se a Tabela 4, que além de sintetizar informações pessoais, evidencia as perspectivas para um futuro curso superior na UFRN.

Tabela 4 - Perfil dos entrevistados 3 e 4 (alunos do PROCEEM).

\begin{tabular}{|c|c|c|c|c|c|}
\hline Nome & $\begin{array}{l}\text { Situação do ensino } \\
\text { médio }\end{array}$ & Vaga que deseja & $\begin{array}{c}\text { Renda } \\
\text { familiar per } \\
\text { capita }\end{array}$ & $\begin{array}{l}\text { Já tentou } \\
\text { ingressar na } \\
\text { UFRN? }\end{array}$ & $\begin{array}{c}\text { Cor ou } \\
\text { Raça }\end{array}$ \\
\hline Entrevistado 3 & $\begin{array}{l}\text { Cursando o } 3^{\circ} \text { Ano } \\
\text { Escola Estadual } \\
\text { Lia Campos }\end{array}$ & $\begin{array}{l}\text { Publicidade } \\
\text { Propaganda } \\
\text { Jornalismo }\end{array}$ & $\mathrm{R} \$ 300,00$ & Não. & Parda \\
\hline Entrevistado 4 & $\begin{array}{l}\text { Ensino médio concluído - } \\
\text { Escola } \quad \text { Estadua } \\
\text { Aristófanes Fernandes }\end{array}$ & $\begin{array}{lll}\text { Serviço } & \text { Social } & \text { ou } \\
\text { Administração. } & \end{array}$ & $\mathrm{R} \$ 330,00$ & $\begin{array}{l}\text { Sim, uma únice } \\
\text { vez. }\end{array}$ & Branca \\
\hline
\end{tabular}

Fonte: elaborada pelo autor.

As características dos entrevistados, mesmo em número reduzido, retratam o perfil de grande parte dos alunos do cursinho,

que em sua maioria são moradores do subúrbio ou periferia da cidade, possuem renda familiar de até dois salários mínimos e renda per capita de até trezentos e cinquenta reais; não possuem condições de arcar com os custos de um curso preparatório e que veem no projeto uma oportunidade única de acesso ao ensino superior público - Entrevistado 2.

No âmbito da UFRN, o cenário de estudantes oriundos de escolas públicas (cerca de 40\%) é menor do que o quantitativo de alunos que concluíram o ensino médio em rede privada (aproximadamente 60\%). Nesse aspecto, Cury (2002) relata que o desafio é superar as dificuldades dos processos seletivos, buscando medidas afirmativas na proporção em que se reconhece que, na atual conjuntura, não se vislumbra em curto prazo, uma melhoria qualitativa na oferta de ensino fundamental e médio.

O quadro atual mostra que a universidade pública de maior tradição e qualidade no ensino favorece o acesso de alunos oriundos de colégios privados. Aos alunos das escolas públicas, com acesso, na maioria das vezes, a um ensino médio público deficiente, cabe disputar o mercado das universidades privadas ou em cursos de menor demanda nas IES públicas.

Outra função do cursinho é justamente auxiliar no equilíbrio entre alunos provenientes de escolas públicas e os que vêm de instituições de ensino particulares , capacitando os alunos a concorrer de 'igual para igual' com os demais". Entrevistado 2. 
Em consonância com as políticas educacionais adotadas pelo Governo Federal, a UFRN passa a partir de 2013, a oferecer todas as vagas da instituição pelo Exame Nacional do Ensino Médio (ENEM) e Sistema de Seleção Unificada (SISU). Identificado a importância dos alunos entenderem o funcionamento desses métodos, perguntou-se aos entrevistados se o PROCEEM preocupa-se em demonstrar essa nova forma de seleção.

A coordenação do Programa afirmou que logo nas primeiras aulas das turmas, a equipe do cursinho dedica alguns momentos da aula para explicar a dinâmica do ENEM, o conteúdo das provas, a interdisciplinaridade das questões e os pontos de cortes utilizados em cada área do conhecimento. Corroborando, o entrevistado 2 cita que "fiquei impressionada com a pró-atividade dos professores em explicar como funciona o ENEM, além de esclarecer minhas dúvidas percebi a complexidade do exame".

Sei que teve uma palestra explicando o funcionamento do ENEM e do SISU, porém no dia, por motivos pessoais, não pude comparecer à aula, agora estou retirando minhas dúvidas pela internet, relata a entrevistada 3.

Nesse aspecto, o cenário que os candidatos encontrarão na UFRN no tocante ao sistema de seleção, é sintetizado na Tabela 5, no qual se verifica os pesos e notas mínimas das provas por área de atuação. É baseado nesses pontos de cortes que o cursinho da UFRN atua, traçando estratégias para que os alunos ultrapassem a pontuação.

Tabela 5 - Vagas reservadas para alunos de escolas públicas e ponto de corte das provas no ingresso ao ensino superior na UFRN.

\begin{tabular}{|c|c|c|c|c|c|c|c|c|c|c|}
\hline \multicolumn{11}{|c|}{ VAGAS RESERVADAS PARA ALUNOS DE ESCOLA PÚBLICA } \\
\hline 2013.2: & $25 \%$ & & & 2014: & $37,5^{\circ}$ & & & 2015: & $50 \%$ & \\
\hline \multicolumn{11}{|c|}{ PESOS E NOTA MÍNIMA (PONTO DE CORTE) DAS PROVAS POR ÁREA } \\
\hline \multirow{2}{*}{ Área } & \multicolumn{2}{|c|}{ Linguagens } & \multicolumn{2}{|c|}{ Matemática } & \multicolumn{2}{|c|}{ C. Humanas } & \multicolumn{2}{|c|}{ C. Natureza } & \multicolumn{2}{|c|}{ Redação } \\
\hline & Peso & Corte & Peso & Corte & Peso & Corte & Peso & Corte & Peso & Corte \\
\hline Biomédica & 1,5 & 400 & 1,0 & 350 & 1,5 & 400 & 3,0 & 450 & 1,5 & 400 \\
\hline Humanística I & 2,0 & 400 & 2,0 & 400 & 2,0 & 400 & 1,0 & 350 & 1,5 & 400 \\
\hline Humanística II & 2,5 & 450 & 1,0 & 350 & 2,5 & 450 & 1,0 & 350 & 1,5 & 400 \\
\hline Tecnológica I & 1,0 & 350 & 2,0 & 400 & 2,0 & 400 & 2,0 & 400 & 1,5 & 400 \\
\hline Tecnológica II & 1,0 & 350 & 3,0 & 450 & 1,0 & 350 & 2,0 & 400 & 1,5 & 400 \\
\hline
\end{tabular}

Fonte: UFRN, 2010.

Nota-se que a porcentagem de vagas reservadas a alunos oriundos de escola pública apresenta aumento nos últimos anos. No segundo semestre de 2013 a porcentagem que era de $25 \%$ passou para uma estimativa de 37,5\% em 2014 e pretende atingir a marca de $50 \%$ em 2015 (alcançado a meta estabelecida pela Lei 12.711/12). Nessa vertente, os "cursinhos populares" como define Freire e Nogueira (2001) possuem papel de destaque, visto que se tornam a oportunidade (talvez única) de muitos estudantes se aperfeiçoarem e concomitantemente contribuem na democratização do acesso e na execução das políticas públicas do Governo.

\subsection{As principais ações de apoio à permanência dos alunos socialmente carentes na UFRN e suas configurações.}

Baseado na premissa de que a expansão não significa democratização (RISTOFF, 2008), as Instituições de Ensino Superior públicas brasileiras evidenciam nos seus Planos de Gestão, estratégias que garantam a redução dos índices de evasão estudantil entre os aprovados. Sobre isso, a Universidade Federal do Rio Grande do Norte, na gestão do então professor José Ivonildo Rêgo, criou em 2003 uma Comissão para estudar a temática e apresentar proposições para uma política de permanência.

Em seu Plano de Gestão 2003-2007, após reuniões com representantes estudantis, professores, comunidade acadêmica, gestores e servidores, a UFRN deu um importante passo no apoio à democratização da permanência dos estudantes socialmente carentes: a ampliação da bolsa 
alimentação e da bolsa residência. Trata-se de políticas que persistem até os dias atuais, viabilizando a permanência do beneficiário no ambiente acadêmico, uma vez que auxiliam a suprir suas necessidades básicas.

Em 2010, por meio do Decreto $n^{\circ}$ 7.234/2010, foi criado o Plano Nacional de Assistência Estudantil (PNAES) que apresenta as diretrizes norteadoras para a definição de programas e projetos dessa natureza, buscando satisfazer as demandas da sociedade e dos alunos. Procurando alinhar as ações desenvolvidas na UFRN à legislação vigente e para atender as novas demandas provindas dos universitários, a nova gestão instituiu outros auxílios, aprimorando os já existentes. A Tabela 6 evidencia a atual configuração das práticas de apoio à permanência dos alunos socialmente carentes na universidade, segundo as áreas do PNAES.

Tabela 6 - Ações de democratização da permanência executadas na UFRN, segundo áreas do PNAES.

\begin{tabular}{l|l|l}
\hline \multicolumn{1}{c}{ Áreas do PNAES } & \multicolumn{1}{c}{ Ação executada na UFRN } & Total de estudantes beneficiários \\
\hline Moradia Estudantil & $\begin{array}{l}\text { Bolsa residência } \\
\text { Auxúlio moradia }\end{array}$ & 777 \\
& Bolsa alimentação & 1.057 \\
\hline Alimentação & Auxílio transporte & 2.748 \\
\hline Transporte & $\begin{array}{l}\text { Criação da Coordenadoria de Atenção à } \\
\text { Saúde do Estudante }\end{array}$ & Ainda não há estimativas oficiais \\
\hline Atenção à saúde & Auxílio atleta & 15 \\
\hline Esporte & Auxílio creche & 74 \\
\hline Creche & $\begin{array}{l}\text { Descentralizado para os departamentos } \\
\text { acadêmicos }\end{array}$ & Ainda não há estimativas oficiais \\
\hline Apoio pedagógico & $\begin{array}{l}\text { Criação da Comissão Permanente de } \\
\text { Apoio ao Estudante com Necessidades } \\
\text { Especiais }\end{array}$ & Ainda não há estimativas oficiais \\
\hline $\begin{array}{l}\text { Acesso e aprendizagem de } \\
\text { estudantes com deficiência. }\end{array}$ &
\end{tabular}

Fonte: elaborado pelo autor.

Verifica-se que em 2014, a UFRN conta com aproximadamente cinco mil e setenta e cinco beneficiados pelas ações de apoio à permanência de estudantes socialmente carentes, representando cerca de $10 \%$ do total de alunos ativos. Além da bolsa residência e bolsa alimentação, a nova gestão criou o auxílio moradia, que diferente dessa, não oferece o espaço físico, mas disponibiliza recursos financeiros que subsidiam o pagamento do aluguel; o auxílio transporte, destinado aos estudantes que residem em zona rural e não possuem condições de arcar com os custos de deslocamento; o auxilio atleta que disponibiliza bolsas para os alunos estudarem e treinarem no campus e o auxílio creche, para estudantes com filhos em idade de pré-escola.

Nas áreas de atenção à saúde e apoio pedagógico ainda não há estimativas oficiais, em virtude da dificuldade em centralizar as informações em um único banco de dados. Nota-se ainda que a bolsa alimentação e o auxílio moradia são os que possuem a maior quantidade de beneficiados, atingindo a marca de três mil oitocentos e cinco estudantes.

O número de beneficiários, principalmente da bolsa alimentação e do auxílio residência cresce, pois além do aumento do número de vagas, a Lei de Cotas proporciona o aumento de alunos socialmente carentes na UFRN. Entrevistado 1.

Quanto ao orçamento, em 2008 a rubrica destinada para a assistência estudantil nas IFES brasileiras foi de aproximadamente R \$ 102 milhões; em 2009 o investimento chegou à quase R\$ 200 milhões; em 2010 ao valor aproximado de R\$ 306 milhões; em 2011 o valor investido foi de $\mathrm{R} \$$ quase 400 milhões, em 2012 o investimento chegou a cerca de R 503 milhões, e no ano de 2013 o repasse foi de aproximadamente $\mathrm{R} \$ 603$ milhões.

Desse montante, procuramos identificar o quanto foi destinado às ações executadas na UFRN. Segundo o Pró-reitor Adjunto de Assuntos Estudantis, em 2012 estima-se que cerca de R\$ 
20 milhões dos recursos foram aplicados na Federal potiguar, valor que aumentou para aproximadamente $\mathrm{R} \$ 30$ milhões no ano subsequente.

Mesmo com os aumentos consecutivos, notamos que o número de alunos socialmente carente vem crescendo de tal forma que os recursos não estão acompanhando a demanda, comenta o entrevistado.

A Coordenadoria de Apoio Pedagógico e Ações de Permanência (CAPAP), vinculada à PróReitoria de Assuntos Estudantis da UFRN é o órgão responsável pela publicação dos editais semestrais de seleção dos beneficiários das bolsas e auxílios oferecidos pela universidade. Nesse aspecto, baseado no Edital 001/2014.2 e nas informações colhidas nas entrevistas, seguem algumas informações referente às ações objetos do estudo (bolsa/auxílio residência; bolsa alimentação e auxílio atleta):

\section{Bolsa/auxílio residência}

Os candidatos a esses auxílios precisam ser aluno socialmente carentes, segundo o disposto na Resolução $n^{\circ} .026$ - CONSAD, de 20 de agosto de 2009; estar regularmente matriculado em número de disciplinas que permita o término do curso dentro do limite máximo de integralização e apresentar, a partir do semestre de concessão do auxílio, desempenho acadêmico satisfatório.

Mediante calendário divulgado em edital, os interessados em se inscrever pela primeira vez deverão registrar interesse pelo Sistema Integrado de Gestão Acadêmica (SIGAA); aderir ao Cadastro Único via sistema; preencher a justificativa para renovação da bolsa, incluindo motivos/dificuldades por não cumprimento de créditos acadêmicos, se for o caso; e comparecer a entrevista social com documento de identificação pessoal, declaração de bolsista (caso necessário), histórico da vida escolar, documentos de identificação dos membros da família e comprovante de renda familiar atualizado. Aos que vão renovar o beneficio, retira-se a realização da entrevista social.

Tabela 7 - Número de beneficiários da bolsa residência.

\begin{tabular}{l|c}
\multicolumn{1}{c}{ Campus } & Residentes Universitários \\
\hline \multicolumn{1}{c}{ Quantitativo } \\
\hline Natal & 597 \\
\hline Facisa & 60 \\
\hline Caicó & 80 \\
\hline Currais Novos & 40 \\
\hline Total de beneficiários & 777 \\
\hline Fonte: UFRN, 2014 &
\end{tabular}

Fonte: UFRN, 2014.

A Tabela 7 evidencia a quantidade de bolsistas residentes nos campi da UFRN pelo estado, que totalizam 777 beneficiários. Desses, 597 estão em Natal e 180 são beneficiários no interior. Ao todo, há 12 residências equipadas com TV a cabo, internet, geladeira, banheiros, quartos com quatro dormitórios e computadores de uso coletivo. As regras de convivência, possíveis problemas de relacionamento e demais questões inerentes ao funcionamento são discutidas em reuniões mensais do Conselho das Residências Universitárias, contando com a representação eleita dos residentes e Pró-Reitoria de Assuntos Estudantis.

Da minha cidade até aqui (capital) são 90 km de distância. Não teria condições de arcar com o deslocamento diário para vim estudar na UFRN. Soube da bolsa residência, participei do processo seletivo e agora vejo que a Bolsa é muito importante na minha formação superior. Entrevistado 6.

Diante do crescente número de alunos que solicitavam o benefício, a UFRN verificou que devido a questões orçamentárias e prazos dos processos licitatórios, a quantidade de residências construídas não acompanhava o ritmo de solicitações semestrais. Dessa forma, desenvolveu-se o 
Auxílio Moradia, que é o pagamento de $\mathrm{R}$ \$ 250,00 para que o estudante possa alugar sua própria residência.

Sabemos que a quantia para uma só pessoa não é suficiente, mas quando se junta 3 ou 4 beneficiários, é possível alugar uma boa residência nas proximidades da UFRN, dado o preço médio dos imóveis na região, relata o Pró-Reitor Adjunto da PROAE.

Tabela 8 - Número de beneficiários do auxílio residência.

\begin{tabular}{|c|c|}
\hline \multicolumn{2}{|c|}{ Auxílio Residência } \\
\hline Campus & Número de beneficiários \\
\hline Natal & 936 \\
\hline Macaíba & 57 \\
\hline Santa Cruz & 51 \\
\hline Caicó & 13 \\
\hline Total de beneficiários & 1.057 \\
\hline
\end{tabular}

\section{Fonte: UFRN, 2014.}

Na Tabela 8, evidencia-se que 1.057 estudantes são beneficiados pelo auxílio residência, totalizando um custo médio mensal de aproximadamente $\mathrm{R} \$ 250.000,00$. A capital é responsável por cerca de $80 \%$ dos beneficiários, o campus de Macaíba e Santa Cruz ocupam a segunda e terceira posição respectivamente e Caicó apresenta pouco mais de $10 \%$ do total. Como uma medida de curto prazo, o auxílio tem se mostrado eficiente, uma vez que oferece moradia estudantil nas proximidades da Academia, porém, a ampliação de espaços próprios garante uma notória economia de recursos em longo prazo.

\section{Bolsa alimentação}

A bolsa alimentação configura-se como uma das principais ações de permanência adotadas na UFRN, principalmente por apoiar o estudante a suprir uma das necessidades básicas dos seres humanos. Os restaurantes universitários já estão estabelecidos no cenário das universidades públicas brasileiras, porém são livres na determinação de preços e políticas de acesso. Nesse aspecto, a UFRN ganha ao garantir a isenção do pagamento ao estudante socialmente carente, mas perde pelo preço da refeição (três reais), maior se comparados a outras IES do Nordeste.

Tabela 9 - Número de beneficiários da bolsa alimentação.

\begin{tabular}{c|c|c|c}
\hline Campus & Bolsista alimentação & $\begin{array}{c}\text { Residentes } \\
\text { (alimentação já } \\
\text { incluída) }\end{array}$ & $\begin{array}{c}\text { Auxílio moradia } \\
\text { (alimentação já incluída) }\end{array}$ \\
\hline Natal & 834 & 597 & 936 \\
\hline Macaíba & 23 & -- & 57 \\
\hline Facisa & 57 & 60 & 51 \\
\hline Caicó & -- & 80 & -- \\
\hline Currais novos & --- & 40 & 2.748 \\
\hline $\begin{array}{c}\text { Total de alunos assistidos } \\
\text { com alimentação }\end{array}$ & \multicolumn{2}{|c}{} \\
\hline
\end{tabular}

Fonte: UFRN, 2014.

A Tabela 9 demonstra a quantidade de bolsista alimentação na UFRN, totalizando 2.748 discentes, sendo 914 usuários apenas da alimentação; 777 residentes universitários e 1.057 beneficiários do auxílio moradia (estes dois últimos com alimentação gratuita incluída). Destaca-se nesse cenário, o quantitativo de usuários no campus de Natal, que alcança a marca de $80 \%$. Nos campus de Caicó e Currais Novos não há restaurantes universitários, portanto as refeições se restringem aos residentes e são servidas por empresas terceirizadas.

Questionado sobre os principais benefícios da ação, o entrevistado 7 evidenciou que além de garantir uma dieta balanceada em seu cotidiano, o auxílio permite a redução de custos, que passam a ser aplicados em outras despesas. Sobre a qualidade da alimentação que é servida, a frase 
"depende da mão do cozinheiro" costuma ser dita costumeiramente para justificar o sabor. Além disso, o espaço físico; o preço para os pagantes e o tempo de espera na fila são alguns pontos a melhorar na execução da referida ação de permanência.

\section{Auxílio atleta}

Criado em 2012 pelo Conselho de Ensino, Pesquisa e Extensão (CONSEPE) da UFRN, o auxílio atleta configura-se como uma das mais novas ações de permanência adotadas. Objetiva incentivar os discentes dos cursos de graduação presenciais que são atletas de alto rendimento e participantes de seleções, através de recurso financeiro mensal no valor de $\mathrm{R} \$ 400,00$ (quatrocentos reais) para auxiliar nas suas despesas com a prática esportiva. Espelha-se em benefícios como a "bolsa atleta" em que bancos brasileiros patrocinam atletas em suas modalidades. A Tabela 10 demonstra de que forma o auxílio é disponibilizado na UFRN.

Tabela 10. Número de beneficiários do auxílio atleta na UFRN.

\begin{tabular}{c|c}
\hline Campus & Número de beneficiários \\
\hline Natal & 14 \\
\hline Caicó & 01 \\
\hline Total de beneficiários & 15 \\
\hline Valor do benefício & $\mathrm{R} \$ 400,00$ \\
\hline
\end{tabular}

\section{Fonte: UFRN, 2014.}

No segundo semestre, serão disponibilizados cinco novas vagas, distribuídas de forma igualitária entre as modalidades de equipe e individuais, que totalizarão 20 (vinte) discentes atendidos. Para solicitar o benefício, além da documentação comum solicitada nos outros auxílios, é necessário que o candidato apresente declaração da Divisão de Atividades Desportivas atestando que faz parte das seleções da UFRN e treina regularmente; currículo desportivo atualizado; comprovante da Federação atestando que o atleta é federado e matriculado em um clube filiado e avaliação médica.

Uma das dificuldades do auxílio atleta é que não são todas as vezes que o aluno socialmente carente é aquele que apresenta os melhores desempenhos nas modalidades esportivas. Sobre isso, o Pró-Reitor Adjunto de Assuntos Estudantis evidencia que "o foco é dá a bolsa a quem dela precise”, porém, nos casos em que não houver candidatos nessas condições, a bolsa é remanejada para os demais. O entrevistado 5 também reconhece a situação e comenta

O benefício proporciona ao aluno atleta a condição financeira mínima para se manter em treinamento e frequentando a universidade. Pode melhorar em relação à seleção, pois se o auxilio está direcionado ao aluno-atleta, conceder o auxilio a outros apenas por questões financeiras perde um pouco do sentido.

Quanto ao fato da cobrança em relação ao desempenho em competições, a beneficiária do auxílio diz não sentir-se pressionada com resultados positivos, e sim motivada a buscar resultados não só individuais, como também para a universidade, já que há o incentivo. Para finalizar, relatamse as conquistas que obteve com o apoio do auxílio atleta, destacando-se: bi-campeonato dos Jogos Universitários do Rio Grande do Norte, vice-campeã da Liga do Desporto Universitário Nacional 2012/2013 e campeã da Liga do Desporto Universitário Nacional 2014.

\section{CONCLUSÃO}

Partindo do pressuposto que a educação superior contempla as características socioeconômicas de um povo, verifica-se que o ensino superior brasileiro reflete as desigualdades sociais existentes em nosso país. Nota-se uma educação superior pública usufruída - em sua maioria - por cidadãos de elevado poder aquisitivo, que detêm condições financeiras de arcar com 
escolas particulares e cursinhos preparatórios. Do outro lado, estão os estudantes socialmente carentes, que concluindo o ensino médio em escola pública, não tiveram a mesma base escolar dos demais, cabendo a eles buscarem cursos de menor concorrência.

Nesse contexto, o presente artigo evidenciou de que forma a Universidade Federal do Rio Grande do Norte atua no apoio à democratização do acesso e da permanência dos estudantes socialmente carentes, relatando-se as principais características do Programa Complementar de Estudos do Ensino Médio (PROCEEM) e as configurações de alguns auxílios disponibilizados, como a bolsa alimentação, bolsa/auxílio residência e auxílio-aleta.

Além de apoiar o ingresso do estudante de escola pública na UFRN, o Programa PROCEEM torna-se ferramenta na união entre teoria e prática, uma vez que todos os professores são discentes de cursos de licenciatura nos campi da universidade. Além disso, auxilia na expansão do ensino no interior, visto que o candidato não precisa se deslocar à capital para se preparar para os processos seletivos. No tocante às ações de permanência, além de permitir que os beneficiados tenham necessidades básicas atendidas, proporcionam, dentre outros, a redução dos índices de evasão, possibilitando economia de recursos com alimentação e moradia e patrocinando o esporte.

As medidas acima descritas colaboram na democratização do acesso e da permanência de estudantes socialmente carentes à universidade pública, porém o cerne do problema constituído pelo ensino fundamental e médio deficientes, precisa ser analisado e devidamente corrigido, pois uma educação de qualidade promoveria a real democratização, de forma que o aluno da escola pública tivesse condições de concorrer em condições de igualdade com os provenientes do ensino privado. Enquanto isso, as ações complementares como as de auxilio à permanência ao estudante ainda se farão necessárias até que as desigualdades de renda sejam amenizadas e todos tenham condições materiais de sobrevivência com dignidade.

Em estudos futuros, recomenda-se detalhar as demais ações executadas na UFRN no apoio ao estudante socialmente carente, comparando os resultados com outras IES públicas do país, objetivando aplicar o benchmarking entre as melhores práticas de cada instituição.

\section{REFERÊNCIAS}

ADORNO, Theodor W. Educação e emancipação. 2. ed. São Paulo: Paz e Terra, 2000.

ANDIFES, Diretório Nacional. Perfil socioeconômico e cultural dos estudantes de graduação das universidades federais brasileiras. Fórum Nacional de Pró-Reitores de Assuntos Comunitários e Estudantis (FONAPRACE). Brasília: TC Gráfica e Editora, 2011.

ARAÚJO, Fabrícia Silva; BEZERRA, Juliane Cristina Bispo. Tendências da Política de Assistência ao Estudante no Contexto da Reforma Universitária Brasileira. 2007.

BRASIL. Constituição da República Federativa do Brasil. Brasília, DF: Senado Federal: Centro Gráfico, 1988.

Decreto $\mathbf{n}^{\mathbf{0}}$ 7.234, de 20 de dezembro de 2010: Institui o Programa Nacional de Assistência Estudantil PNAES. Brasília, 2010. Disponível em: http://www.planalto.gov.br/ccivil_03/_Ato20072010/2010/Decreto/D7234.htm. Acesso em 01. jul.2014.

. Lei n. ${ }^{\circ}$ 12.711, de 30 de agosto de 2012. Dispõe sobre o ingresso nas universidades federais e nas instituições federais de ensino técnico de nível médio e dá outras providências. Brasília: Diário Oficial da Republica Federativa do Brasil, 2012.

Ministério da Educação. Painel de Controle do Ministério da Educação. 2013. Disponível em: http://painel.mec.gov.br/. Acesso em 17.jul.2014.

. Projeto de Lei 8.035/10. Aprova o Plano Nacional de Educação para o decênio 2011-2020, 2011. Disponível em: http://portal.mec.gov.br/index.php?option=com_content\&id=16478\&Itemid=1107. Acesso em 21.jun.2014. 
Portaria Normativa No 39, de 12 de Dezembro de 2007. Institui o Programa Nacional de Assistência Estudantil - PNAES. Brasília, 2007. Disponível em: http://portal.mec.gov.br/arquivos/pdf/portaria_pnaes.pdf. Acesso em 17.jul.2014.

CATANI, Afrânio Mendes, OLIVEIRA, João Ferreira. Educação Superior no Brasil: reestruturação e metamorfose das universidades públicas. Petrópolis/RJ: Vozes, 2002.

CURY, Carlos Roberto Jamil. Direito à educação: direito à igualdade, direito à diferença. Cadernos de Pesquisa. São Paulo, 2002.

FINATTI, Betty Elmer. Assistência Estudantil na Universidade Estadual de Londrina/UEL. Dissertação. Universidade Estadual de Londrina: Londrina, 2007

FONAPRACE. Fórum Nacional de Pró-Reitores de Assuntos Comunitários e Estudantis - Dez Encontros. Goiânia, 1993.

FREIRE, Paulo; NOGUEIRA, Adriano. Que fazer: teoria e prática em educação popular. Petrópolis: Vozes, 2001

GEMAA. Grupo de Estudos Multidisciplinares da Ação Afirmativas, 2011. Ações afirmativas. UFRJ: 2011.

GIL, Antônio Carlos. Como elaborar projetos de pesquisa. 5. ed. São Paulo: Atlas, 1999.

GOMES, Nilma Lima; MARTINS, Aracy Alves. Afirmando direitos: acesso e permanência de jovens negros na universidade. Belo Horizonte: Autêntica, 2004.

HAMBURGUER, Ernst Wolfgang. Seletividade Social e o vestibular.In:Seminário vestibular hoje: coletânea de textos. Brasília: MEC, 1987.

HERMIDA, Jorge Fernando. Acciones afirmativas e inclusión educacional em Brasil. Buenos Aires: Consejo latino americano de ciências sociales, 2006.

HULGÅRD, L.; FERRARINI, A.V. Inovação social: rumo a uma mudança experimental na política pública? Revista Ciências Sociais, Unisinos, 2010.

INEP. Instituto Nacional de Estudos e Pesquisas Educacionais Anísio Teixeira. Censo da Educação Superior 2012 resumo técnico. Disponível em: http://portal.mec.gov.br/index.php?option=com_content\&view=article\&id=19077. Acesso em: 13. jun. 2014.

LEITE, J. L. Política de cotas no Brasil: política social? Florianópolis, v. 14, n. 1. 2011.

MEAD, L. M. Public Policy: Vision, Potential, Limits. PolicyCurrents, 1995.

Mello, M. F. F.; SIlVA, F. C; MOURA, L. S. A Adoção da Política de Cotas nas Universidades Públicas Brasileiras e sua Repercussão no Ensino Superior do País.In: Encontro de administração púbica e governo EnAPG, Anais. São Paulo, 2006.

MOEHLECKE, Sabrina. Ação afirmativa: história e debates no Brasil. Cadernos de Pesquisa, São Paulo, v.117, 2002.

PEIXOTO, Maria do Carmo Lacerda (org). Universidade e Democracia: experiências e alternativas para ampliação do acesso à universidade pública brasileira. Belo Horizonte: Ed. UFMG, 2004.

PROCEEM. Processo seletivo simplificado para bolsista do PROCEEM: edital 001/2014. UFRN, 2014.

QUEIROZ, Delcele Mascarenhas. Desigualdades no ensino superior: cor, status e desempenho. Disponível em: www.andep.org.br. Acesso em 22.jun.2014.

RISTOFF, Dilvo; SEVEGNANI, Palmira (org). Democratização do campus. Brasília: Instituto Nacional de Estudos e Pesquisas Educacionais Anísio Teixeira, 2006.

SANTOS, C.M. O perfil econômico dos candidatos e dos matriculados pelos vestibulares da UNESP em 1996: o grau de elitização dos cursos de Marília e Araçatuba. São Paulo: Dissertação - Universidade Estadual Paulista, 1996.

TABORDA, Camila Oliveira et al.A meritocracia e o ensino superior. Coleção grandes temas do Conexão de Saberes: prática pedagógica e a lógica meritória na universidade. UFPR, 2006.

TEIXEIRA, P. N; ROCHA, V; BISCAIA, R; CARDOSO, M. F. Competition and diversity in higher education: an empirical approach to specialization patterns of Portuguese institutions. HigherEducation, v.63, 2012.

UNESCO. Análise sobre a Expansão das Universidades Federais 2003-2012. Organização das Nações Unidas para a Educação, Ciência e Cultura. Brasília. 
http://portal.mec.gov.br/index.php?option=com_docman\&task=doc_download\&gid=12386\&Itemid= Acesso em 22.jun.2014.

UNIVERSIDADE FEDERAL DO RIO GRANDE DO NORTE. Programa PROCEEM. Natal: Editora do Campus, 2007.

VASCONCELOS, Natalia Batista. Programa Nacional de Assistência Estudantil: Uma análise da evolução da assistência estudantil ao longo da história da educação superior no Brasil. Revista da Católica, Uberlândia, v.2, n.3, 2010 .

WANDERLEY, Luiz Eduardo W. Universidades e sociedades: consensos e dissensos. Serviço Social \&Sociedade: São Paulo, 2005.

WASHINGTON, V.; HARVEY, W. Affirmative rethoric, negative action.East Lansing, MI: ASHE-ERIC, 1999.

WHITAKER, D. A.; FIAMENGUE, E. C. Ensino médio: função do estado ou da empresa? Campinas: Educação \& Sociedade, 2001.

ZANDONÁ, Norma da Luz. O espaço do contra poder: o acesso à universidade pública e o perfil socioeconômico educacional dos candidatos ao vestibular da UFPR. Tese. Curitiba, 2005. 